\title{
Evidence That Separate Neural Circuits in the Nucleus Accumbens Encode Cocaine Versus "Natural" (Water and Food) Reward
}

\author{
Regina M. Carelli, Stephanie G. ljames, and Alison J. Crumling \\ Department of Psychology, The University of North Carolina at Chapel Hill, Chapel Hill, North Carolina 27599-3270
}

\begin{abstract}
Electrophysiological recording procedures were used to examine nucleus accumbens (Acb) cell firing in rats trained to press a lever on a multiple schedule [ fixed ratio (FR)1, FR1] for either two "natural" reinforcers (food and water), or a natural reinforcer and intravenous self-administration of cocaine. Of 180 cells recorded during water and food reinforcement ( $n=13$ rats), 77 neurons were classified as phasically active, exhibiting one of three well-defined types of patterned discharges relative to the reinforced-response (Carelli and Deadwyler, 1994). Of the 77 phasic cells, the majority $(68 \%)$ showed similar types of patterned discharges across the two natural reinforcer conditions. In contrast, of 127 neurons recorded during water and cocaine reinforcement ( $n=8$ rats), only 5 of 60 phasically active cells (8\%) exhibited similar types of patterned discharges relative to
\end{abstract}

A fundamental issue in drug abuse research concerns how abused substances such as cocaine gain access to the brain "reward" circuit and lead to drug addiction. As stated by Wise (1982, 1983, 1997), it is likely that the brain did not evolve to process information about abused substances. Instead, drugs of abuse likely "tap into" an existing neural circuit that normally processes information about natural reinforcers such as food, water, and sexual behaviors. In this regard, the nucleus accumbens (Acb) appears to be a key neural substrate through which natural reinforcers and abused substances exert their reinforcing actions (Di Chiara, 1995; Koob and Nestler, 1997; Bardo, 1998; Koob, 1998).

A number of studies support the importance of the Acb in mediating the rewarding properties of natural reinforcers (Hoebel, 1997; Salamone et al., 1997; Stratford and Kelley, 1997; Wise, 1998). For example, microdialysis and voltammetry studies in behaving rats have revealed significant increases in dopamine levels in the Acb during feeding, drinking, and sexual behaviors (Pfaus et al., 1990; Wenkstern et al., 1993; Di Chiara, 1995; Wilson et al., 1995; Richardson and Gratton, 1996; Taber and Fibiger, 1997). Likewise, feeding behavior has been induced in rats via microinfusion of non-NMDA glutamate receptor antagonists or GABA agonists into the shell region of the Acb (Kelley and Swanson, 1997; Stratford and Kelley, 1997; Stratford et al., 1998). Furthermore, electrophysiological studies in behaving animals showed patterned activation of Acb neurons relative to operant responding for juice reinforcement in monkeys (Bowman

Received Jan. 7, 2000; revised March 10, 2000; accepted March 16, 2000.

This work was supported by National Institute on Drug Abuse Grant DA10006 and The Whitehall Foundation. We thank Drs. Patricia Sue Grigson, Michael J. DeVito, and Sam A. Deadwyler for their helpful comments.

Correspondence should be addressed to Dr. Regina M. Carelli, Department of Psychology, The University of North Carolina at Chapel Hill, CB\# 3270, Davie Hall, Chapel Hill, NC 27599-3270. E-mail: rcarelli@unc.edu.

Copyright (C) 2000 Society for Neuroscience $0270-6474 / 00 / 204255-12 \$ 15.00 / 0$ water- and cocaine-reinforced responding. The remaining 55 phasic cells $(92 \%)$ displayed patterned discharges relative to the cocaine-reinforced response ( $n=26$ cells), or relative to the water-reinforced response ( $n=29$ cells), but not both. For some rats $(n=3)$, food was substituted for water in the task. Again, the majority of phasic neurons (13 of 14 cells, 93\%) exhibited nonoverlapping firing patterns across the drug and natural reinforcer conditions. These findings indicate that in the well-trained animal, cocaine activates a neural circuit in the Acb that is largely separate from the circuit that processes information about food and water reward.

Key words: nucleus accumbens; reward; water; food; cocaine; self-administration

et al., 1996; Schultz et al., 1997; Hollerman et al., 1998; Schultz, 1998; Tremblay et al., 1998) and water reinforcement in rats (Carelli and Deadwyler, 1994).

Electrophysiological studies in behaving animals also support a role of the Acb in cocaine reinforcement (Carelli and Deadwyler, 1994, 1996, 1997; Chang et al., 1994, 1998; Bowman et al., 1996; Peoples and West, 1996; Peoples et al., 1998). We previously reported that a subset of Acb neurons exhibits four types of patterned discharges relative to cocaine-reinforced responding (Carelli and Deadwyler, 1994). One neuronal cell type is observed only during cocaine self-administration [type PR+RF or "cocaine-specific" (CSp)]. The other three cell types are observed during either cocaine self-administration or water reinforcement and are categorized by cells showing an anticipatory increase in firing rate within seconds preceding the reinforced response (type PR), and by cells that are either excited (type RFe) or inhibited (type RFi) after response completion. The similarity in firing patterns across the two reinforcer conditions suggests that cocaine activates a neural circuit in the Acb that normally processes information about natural reinforcers. However, in the aforementioned study different Acb neurons were recorded during behavioral responding for water and cocaine. Therefore, it could not be definitively concluded that cocaine activates the same cells (i.e., the same circuit in the Acb) that normally process information about water reinforcement. To resolve this, two studies were completed that examined the activity of the same Acb neurons in rats responding on a multiple schedule for either two distinct natural reinforcers (water and food), or a natural reinforcer and intravenous self-administration of cocaine.

\section{MATERIALS AND METHODS}

Food and water reinforcement. Male, Sprague Dawley rats (Harlan Sprague Dawley, Indianapolis, IN), $\sim 90$ - to 120 -d-old and weighing 275-350 gm were used as subjects $(n=13)$. Eight of 13 animals used here 
were previously implanted with microwire electrode arrays and tested during a multiple schedule for water and cocaine reinforcement (see below). For these subjects, training on the water/food multiple schedule began $\sim 7-10 \mathrm{~d}$ after the last water/cocaine experiment. Because it was possible that previous cocaine exposure could alter the responsiveness of Acb neurons, the remaining five animals were trained only on the multiple schedule for water and food reinforcement and had no previous exposure to cocaine. Results indicated no appreciable differences with respect to behavioral response patterns and types of neuronal firing patterns and therefore the data were pooled across all subjects. Animals were housed individually and maintained at no $<85 \%$ of their preoperative body weight by regulation of food and water intake. Specifically, animals were given $10 \mathrm{ml}$ of water per day (in addition to $1.0-1.5 \mathrm{ml}$ of water consumed during the session) throughout the duration of the experiment. Food regulation consisted of $\sim 9 \mathrm{gm}$ of Purina laboratory pellets per day during training, and this was gradually increased to 20 $\mathrm{gm} / \mathrm{d}$ (in addition to $1.2-1.5 \mathrm{gm}$ of food consumed during the session) as behavioral responding became stable.

Experimental sessions were conducted in a $43 \times 43 \times 53 \mathrm{~cm}$ Plexiglas chamber (Med Associates, St. Albans, VT) housed within a commercial sound-attenuated cubicle (Fibrocrete, Crandall, GA). One side of the chamber contained two retractable levers (Coulbourn Instruments, Allentown, PA) located $17 \mathrm{~cm}$ apart with a water trough between the levers ( $7 \mathrm{~cm}$ from each lever and $2.5 \mathrm{~cm}$ from the bottom of the chamber). The food dispenser was located on the same side as the levers and water trough, $1 \mathrm{~cm}$ to the right of the second lever $(2.5 \mathrm{~cm}$ from the bottom of the chamber). Note that because there are only two levers in each chamber, the food-associated lever used here was originally associated with cocaine reinforcement for the eight animals with previous cocaine experience. However, different auditory cues were associated with water-, food-, and cocaine-reinforced responding (see below).

Rats were initially trained to press one lever on a fixed ratio 1 (FR1) schedule of reinforcement for $0.05 \mathrm{ml}$ of water delivered via a fluid injection assembly (syringe pump) into a drinking spout. Water delivery was signaled by retraction of the lever $(20 \mathrm{sec})$ and the onset of a clicking tone stimulus (10 clicks/sec: $80 \mathrm{~dB}, 800 \mathrm{~Hz} ; 1 \mathrm{sec})$. Animals were then trained to press a second lever in the chamber (FR1) for food reinforcement (1 Noyes precision food pellet per response), signaled by a tone stimulus $(72 \mathrm{~dB}, 800 \mathrm{~Hz} ; 1 \mathrm{sec})$. Next, a multiple schedule of reinforcement was implemented in which animals had access to the waterreinforced lever (10-15 $\mathrm{min}$ ), followed by a $20 \mathrm{sec}$ time out period (no lever extended), and extension of the food-reinforced lever (10-15 $\mathrm{min})$. Illumination of a cue light positioned $6.5 \mathrm{~cm}$ above each lever signaled the phase (water or food) of the multiple schedule. Observation of the animals during the experiments revealed that each rat turned toward the dispensers after completion of the operant response without locomoting around the chamber and consumed the reinforcer (typically within 0.5$1.0 \mathrm{sec}$ ). This behavior was typically observed from the first trial of each phase of the multiple schedule. The order of reinforcer availability (water or food) was varied across sessions such that the same reinforcer was not always given first every day. The same types of neuronal firing patterns were observed regardless of reinforcer order. Nevertheless, data included in the analysis were balanced such that half of the sessions began with water reinforcement, and the other half of the sessions began with food reinforcement.

Water and cocaine reinforcement. Animals $(n=8)$ were housed individually and maintained at no $<85 \%$ of their preoperative body weight beginning 1 week after catheter implantation by regulation of food and water intake. Specifically, animals were given $10 \mathrm{ml}$ of water (in addition to $1.0-1.5 \mathrm{ml}$ of water consumed during the session) and $20 \mathrm{gm}$ of Purina laboratory pellets each day for the duration of the experiment. Animals were surgically implanted with a catheter into their jugular vein and trained to self-administer cocaine, as previously described (Carelli and Deadwyler, 1994). Briefly, subjects were anesthetized with ketamine hydrochloride $(100 \mathrm{mg} / \mathrm{kg})$ and xylazine hydrochloride $(20 \mathrm{mg} / \mathrm{kg})$ and surgically implanted with a catheter into the jugular vein. The catheter was then routed subcutaneously to the back and attached to a coupling assembly. The fluid injection assembly (syringe pump) was connected to a swivel system in the experimental chambers, which enabled intravenous infusion of cocaine during self-administration sessions.

One week after catheter implantation, rats were trained to selfadminister cocaine during $2 \mathrm{hr}$ experimental sessions. The beginning of the session was signaled by the onset of a cue light positioned $6.5 \mathrm{~cm}$ above the lever and extension of a retractable lever. Lever depression on a FR1 schedule resulted in intravenous cocaine delivery $(0.33 \mathrm{mg} /$ infusion, dissolved in sterile heparinized saline vehicle) over a $6 \mathrm{sec}$ period via a computer-controlled syringe pump (model PHM-100; Med Associates). Each drug infusion was signaled immediately by retraction of the lever $(20 \mathrm{sec})$ and the onset of a tone stimulus $(65 \mathrm{~dB}, 2900 \mathrm{~Hz})$ presented over a $20 \mathrm{sec}$ interval (14 $\mathrm{sec}$ beyond the pump duration). During the $20 \mathrm{sec}$ postresponse interval, lever press responding had no programmed consequences.

After the onset of stable self-administration responding (2-3 weeks), animals were trained to press a second lever in the chamber for water reinforcement $(0.05 \mathrm{ml} /$ response, FR1). Water delivery was signaled by retraction of the lever $(20 \mathrm{sec})$ and the onset of a clicking tone stimulus (10 clicks/sec; $80 \mathrm{~dB}, 800 \mathrm{~Hz} ; 20 \mathrm{sec}$ ). Next, a multiple schedule of water and cocaine reinforcement was implemented. Animals had access to the water-reinforced lever for $10-15 \mathrm{~min}$, followed by a $20 \mathrm{sec}$ time out period (no lever extended), and extension of the cocaine-reinforced lever $(2 \mathrm{hr})$. Illumination of a cue light above each lever signaled the phase (cocaine or water) of the multiple schedule. Observation of the animals revealed that each rat typically turned toward the water dispenser and immediately consumed the water reinforcer during the water reinforcement phase of the multiple schedule. During the cocaine reinforcement phase, animals typically completed a "burst" of responses at the start of the phase (termed "load-up" behavior) then exhibited stereotypic behavior characteristic of cocaine self-administration in rats (Carelli and Deadwyler, 1994). The order of reinforcer availability (water or cocaine) was varied across sessions as noted for experiment 1 . Likewise, data included in the analysis were balanced such that half of the sessions began with water reinforcement, and the other half of the sessions began with cocaine reinforcement, similar to experiment 1 .

After completion of the last experiment, food was substituted for water reinforcement in the task for three animals. Specifically, the animals were trained to respond on a multiple schedule (FR1, FR1) for food reinforcement (1 Noyes precision pellet per response) and cocaine $(0.33 \mathrm{mg} / \mathrm{inf})$ self-administration using the same parameters described for the water/ cocaine multiple schedule.

Electrophysiological recordings. When behavioral responding was stable, animals were anesthetized with ketamine hydrochloride $(100 \mathrm{mg} / \mathrm{kg})$ and xylazine hydrochloride $(20 \mathrm{mg} / \mathrm{kg})$ and prepared for chronic extracellular recording in the Acb as previously described (Carelli and Deadwyler, 1994). Electrodes were custom-designed and purchased from a commercial source (NB Labs, Denison, TX). Each array consisted of "bundles" of eight microwires (50 diameter) arranged in three rows. The first row contained two wires with a tip separation of $\sim 0.25 \mathrm{~mm}$. The second and third rows contained three wires (tip separation of $\sim 0.25$ $\mathrm{mm})$. The entire array spanned an approximate distance of $0.35-0.65$ $\mathrm{mm}$ anteroposterior (AP) and 0.35 to $0.65 \mathrm{~mm}$ mediolateral (ML). Each array also contained a ground wire that was inserted $3-4 \mathrm{~mm}$ into the brain, ipsilateral to the array and $\sim 5 \mathrm{~mm}$ caudal to bregma. Arrays were permanently implanted bilaterally into the Acb [AP, +1.7 mm; ML, 1.5 $\mathrm{mm}$; dorsoventral (DV), 6.0-7.5 mm, relative to bregma, level skull].

After electrode implantation, presurgical behavioral performance was reestablished (typically within $1 \mathrm{~d}$ ), and neuronal activity was recorded during all subsequent behavioral sessions. Electrophysiological procedures have been described in detail previously (Carelli and Deadwyler, 1994, 1996; Carelli et al., 1999). Briefly, before the start of each session, the subject was connected to a flexible recording cable attached to a commutator (Med Associates), which allowed virtually unrestrained movement within the chamber. The headstage of each recording cable contained 16 miniature unity-gain field effect transistors (common mode rejection was $35 \mathrm{~dB}$ at the headset pins at $1 \mathrm{kHz}$ measured in a test setup). Acb activity was typically recorded differentially between each active and the inactive (reference) electrode from the permanently implanted microwires. The inactive electrode was examined before the start of the session to verify the absence of neuronal spike activity and served as the differential electrode for other electrodes with cell activity. Online isolation and discrimination of neuronal activity was accomplished using a neurophysiological system commercially available (MNAP system; Plexon, Dallas, TX). Multiple window-discrimination modules and high-speed analog-to-digital signal processing in conjunction with computer software enabled isolation of neuronal signals based on waveform analysis. The neurophysiological system incorporated an array of digital signal processors (DSPs) for continuous spike recognition. The DSPs provided a continuous parallel digital output of neuronal spike events to a Pentium computer. A 486 computer controlled behavioral events of the experiment (Med Associates) and sent outputs corresponding to each event to the MNAP box to be time-stamped along with 
the neural data. The neurophysiological system has the capability of recording up to four neurons per microwire using real-time discrimination of neuronal action potentials. However, in the present study, typically one or two neurons were recorded per microwire (Chang et al., 1994; Nicolelis et al., 1997). Criteria for identifying different neurons on a single wire has been described in detail elsewhere (Chang et al., 1994; Nicolelis et al., 1997; Carelli et al., 1999; Nicolelis, 1999). Briefly, discrimination of individual waveforms corresponding to a single cell was accomplished using template analysis procedures or time-voltage boxes provided by the neurophysiological software system (MNAP system; Plexon). The template analysis procedure involves taking a "sample" of the waveform and building a template of that extracellular waveform. Subsequent neurons that "match" this waveform are included as the same cell. When using time-voltage boxes, a sample of the waveform is taken, then the experimenter superimposes two boxes onto it (typically one on the ascending limb and the other on the descending limb of the extracellular waveform). Subsequent sampled neurons are accepted as valid when they pass through both boxes. Neurons included in the analysis were recorded during one behavioral session per animal, however, there was one reported instance in which the same cell was recorded across 2 consecutive days. Criteria for identification of the same neuron across days included: (1) the cell was recorded from the same microwire across the $2 \mathrm{~d},(2)$ the neuron exhibited the same waveform characteristics in terms of amplitude, duration, polarity, etc., and (3) the interspike interval was similar across the 2 d (Nicolelis et al., 1997; Chang et al., 1998; Carelli et al., 1999). The parameters for isolation and discrimination of single-unit activity were determined and saved using the neurophysiological software and modified before each session as needed, for example, to discriminate "new" neurons that appeared on a given microwire electrode, or to change the inactive electrode.

Data analysis. Neural activity was characterized via raster displays and perievent histograms (PEHs) showing the activity of each cell during a $20 \mathrm{sec}$ time interval that bracketed the water-, food-, or cocainereinforced lever press. Types of patterned discharges (termed PR, RFe, $\mathrm{RFi}$, and $\mathrm{PR}+\mathrm{RF}$ ) have been described in detail previously and were characterized by differential mean firing rates within four time epochs in each PEH (Carelli and Deadwyler, 1994). The four time epochs within each PEH were (1) "baseline", defined as the time period ( -10 to -7.5 sec) before the initiation of the reinforced lever press response; (2) "response", defined as the time period $(-2.5$ to $0 \mathrm{sec})$ immediately before and during the execution of the reinforced response; (3) "reinforcement", defined as the time period $(0$ to $+2.5 \mathrm{sec})$ immediately after the response; and (4) "recovery", defined as the time period ( +7.5 to +10 sec) after the reinforced response.

Criteria for classifying each neuron into one of the four types of patterned discharges were as follows. A neuron was classified as type PR if it showed a $40 \%$ or greater increase in firing rate within a 1 sec period of maximal discharge during the response epoch only, compared to its respective baseline activity. If a neuron exhibited a $40 \%$ increase in activity that began in the response phase and extended without interruption into the reinforcement phase, it was also classified as a type PR neuron. A neuron was classified as type RFe if it showed a $40 \%$ or greater increase in cell firing within a $1 \mathrm{sec}$ period of maximal discharge during the reinforcement phase only (i.e., short duration type RFe cells), or if it exhibited a $40 \%$ increase in firing during both the reinforcement and recovery phases (long duration type RFe cells), compared to its respective baseline activity. Neurons classified as type RFi had a $40 \%$ or greater decrease in firing rate within a $1 \mathrm{sec}$ period during the response and/or reinforcement epoch, compared to its respective baseline firing rate. A neuron was categorized as type $\mathrm{PR}+\mathrm{RF}$ if it displayed a $40 \%$ or greater increase in activity during a $1 \mathrm{sec}$ period within both the response and reinforcement epochs (but not the recovery phase), compared to its respective baseline rate. In addition, neurons classified as type PR+RF had to exhibit an inhibition in activity to baseline levels between the two peak discharges. "Nonphasic" neurons exhibited similar firing rates across the four time epochs without the $40 \%$ changes in activity characteristic of the four types of patterned discharges described above.

Statistical confirmation of the above cell type classification was accomplished using a repeated-measures $t$ test that compared mean peak (types $\mathrm{PR}, \mathrm{RFe}$, and $\mathrm{PR}+\mathrm{RF}$ ) or trough (type $\mathrm{RFi}$ ) firing rates for all neurons of a given type, to their respective baseline rates. In addition, a repeatedmeasures $t$ statistic was used to examine whether all neurons of a given cell type exhibited similar mean peak/trough changes in activity relative to the water- versus food-reinforced response (experiment 1).

Latency to onset of neuronal discharge for individual neurons was determined as follows. Mean firing rates were examined within consecutive $80 \mathrm{msec}$ periods (bins) during the epoch in which the cell exhibited its peak or trough changes in activity. Latency of onset was defined as the first of three consecutive $80 \mathrm{msec}$ bins in which firing rate consistently increased (for types PR, RFe cells) or decreased (for type RFi cells) by $40 \%$ compared to the respective baseline activity of each cell.

Population histograms of normalized cell firing were generated for all phasically active neurons during the $20 \mathrm{sec}$ time interval that bracketed the water-, food-, or cocaine-reinforced response. Specifically, the neuronal firing patterns of all $\mathrm{PR}, \mathrm{RFe}, \mathrm{RFi}$, and $\mathrm{PR}+\mathrm{RF}$ cells recorded during the multiple schedule for water and food, or water and cocaine reinforcement were presented as composite PEHs summed over all cells of a specific type and normalized relative to the overall firing rate of each neuron. Normalization of cell firing allowed for an examination of changes in the activity of populations of cells regardless of differences in overall rates of firing between individual neurons (Carelli and Deadwyler, 1994).

Histology. After the completion of the last experiment, animals were anesthetized with sodium pentobarbital $(50 \mathrm{mg} / \mathrm{kg})$, and a $10 \mathrm{amp}$ current passed for $6 \mathrm{sec}$ through two recording electrodes (for two rats, three recording electrodes) in the array on each side of the brain. Microwires chosen for marking typically exhibited large isolated spikes and well-characterized firing patterns during a behavioral session. The rat was perfused with $10 \%$ formalin, and the brain was removed, blocked, and sectioned $(40 \mu \mathrm{m})$ throughout the rostrocaudal extent of the Acb. Alternating sections were stained for either thionin or tyrosine hydroxylase. All sections were counterstained with Prussian blue to reveal a blue dot reaction product corresponding to the location of the marked electrode tip (Green, 1958; Carelli and Deadwyler, 1994). The procedure used to reconstruct electrode placements was as follows. Serial sections were examined under a light microscope, and the locations of marked electrode tips were plotted for all subjects on coronal sections taken from the stereotaxic atlas of Paxinos and Watson (1997). Given the arrangement of our microelectrode array, unmarked wires were in close proximity to marked wires and were determined by estimation of termination of the microwire tracks in serial sections. The point at which the unmarked electrode track was at its most ventral position was plotted as the "estimated" placement. Position within the various regions of the Acb (core, shell, and rostral pole) and boundaries between these regions were determined by examination of marked and unmarked electrode tip locations in relation to: (1) the borders of the tyrosine hydroxylase stain at the level of the rostral pole and caudal Acb regions, (2) precise "landmarks" in the brain, for example, the anterior commissure, and (3) the anatomic arrangement of the Acb as depicted in the stereotaxic atlas of Paxinos and Watson (1997). Although it is difficult to establish a clear boundary between the core and the adjacent ventral portions of the caudate putamen (CPv) (Heimer et al., 1995), electrode tip placements were considered to be in the latter region $(\mathrm{CPv})$ if they were within $\sim 0.8$ $\mathrm{mm}$ dorsal to the borders of the Acb core outlined in Paxinos and Watson (1997). Although electrode placements were verified to be primarily in the Acb (see below), it was difficult to determine with $100 \%$ accuracy the one-to-one correspondence between electrode tip marking and cell type, therefore this issue was not addressed here.

\section{RESULTS}

Water and food reinforcement: behavioral performance

Figure 1 shows the behavioral (lever press) response pattern for a single, well-trained animal during the multiple schedule for water and food reinforcement. The cumulative record from time $0-600$ sec shows the water reinforcement portion of the session in which the animal completed 25 reinforced responses with a mean intertrial interval (INT) of $22.73 \pm 0.38 \mathrm{sec}$. This was followed by a 20 sec time out period (indicated by double line at time 600). The record for the remainder of the session shows the food reinforcement phase in which the animal completed 29 reinforced responses with a mean INT of $20.84 \pm 0.06 \mathrm{sec}$. The similarity in behavioral responding across the two natural reinforcer conditions was evident across all animals $(n=13)$ and was observed regardless of the order of reinforcer in the session. In summary, the mean number of responses for all animals during water reinforcement was $28.20 \pm 1.62$ responses with a mean INT of 


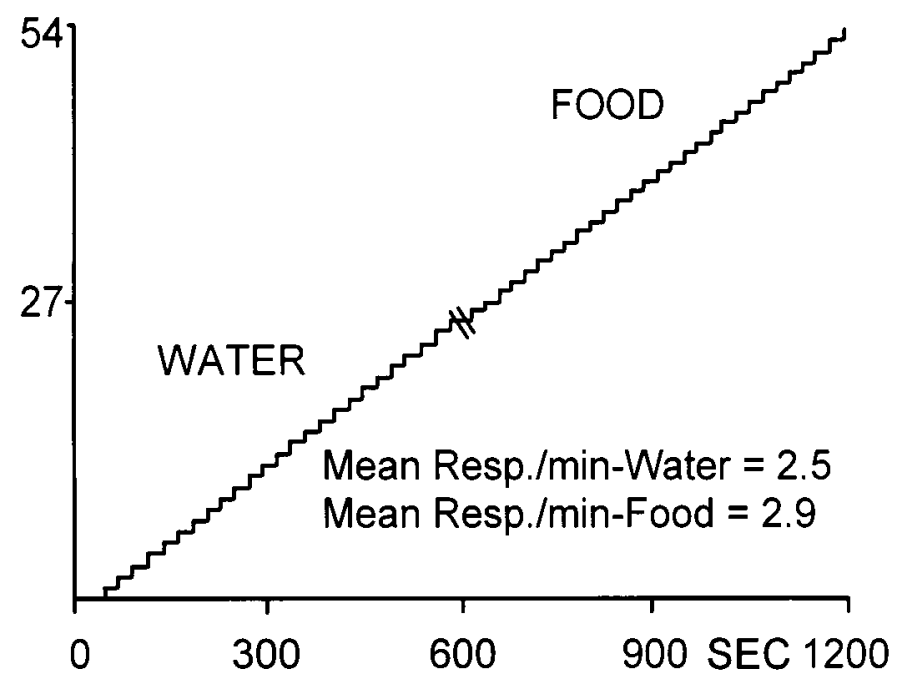

Figure 1. Cumulative record showing the behavioral (lever press) response pattern for a single animal during the multiple schedule for water and food reinforcement. The animal completed 25 responses for water $($ mean INT $=22.73 \pm 0.38 \mathrm{sec})$ and 29 responses for food $($ mean INT $=$ $20.84 \pm 0.06 \mathrm{sec}$ ). Each upward deflection indicates a reinforced response (FR1). The $y$-axis is the number of lever presses. Double line at time 600 $\mathrm{sec}$ indicates time out period $(20 \mathrm{sec})$. Resp, Responses.

$23.02 \pm 1.06 \mathrm{sec}$. The mean number of responses during food reinforcement was $27.80 \pm 1.56$ responses with a mean INT of $24.80 \pm 1.79 \mathrm{sec}$.

\section{The majority of Acb neurons exhibit similar, overlapping neuronal firing patterns during water and food reinforcement}

A total of 180 neurons were recorded during behavioral responding for water and food reinforcement. In general, cells fired at similar rates across the two natural reinforcer conditions (overall mean for water $=4.10 \pm 0.53 \mathrm{~Hz}$; overall mean for food $=4.11 \pm$ $0.43 \mathrm{~Hz})$. Of 180 neurons, 77 cells $(43 \%)$ were classified as phasically active, exhibiting one of three types of neuronal firing patterns described in detail previously (Carelli and Deadwyler, 1994). Briefly, an increase in firing rate immediately before the reinforced lever press response designated some neurons as "preresponse" or PR cells. Other types of neurons exhibited excitation [type "reinforcement-excitation" (RFe)] or inhibition [type "reinforcement-inhibition" (RFi)] in firing rate immediately after the operant reinforced response. The remaining 103 neurons $(57 \%)$ exhibited no change in firing rate (increase or decrease) relative to the water- or food-reinforced response [type "nonphasic" (NP)].

The first major finding of this report is that, of the 77 phasically active neurons, 52 cells (68\%) exhibited similar types of neuronal firing patterns across the two natural reinforcer conditions. An example of a single Acb neuron with type PR activity across the two reinforcer conditions is shown in Figure 2. The PEHs (left) show that the Acb cell exhibited anticipatory increases in firing rate relative to both the water- and food-reinforced response, characteristic of type PR cells. The raster display (right) shows the activity of the same Acb cell shown in the PEHs, across all trials of the session. During the water reinforcement phase (trials 1-22), the cell exhibited a robust increase in firing rate within 1 sec preceding all water-reinforced responses, with a marked decline in firing within $0.5 \mathrm{sec}$ after response completion. During the food reinforcement phase (trials 23-44), the Acb cell contin-

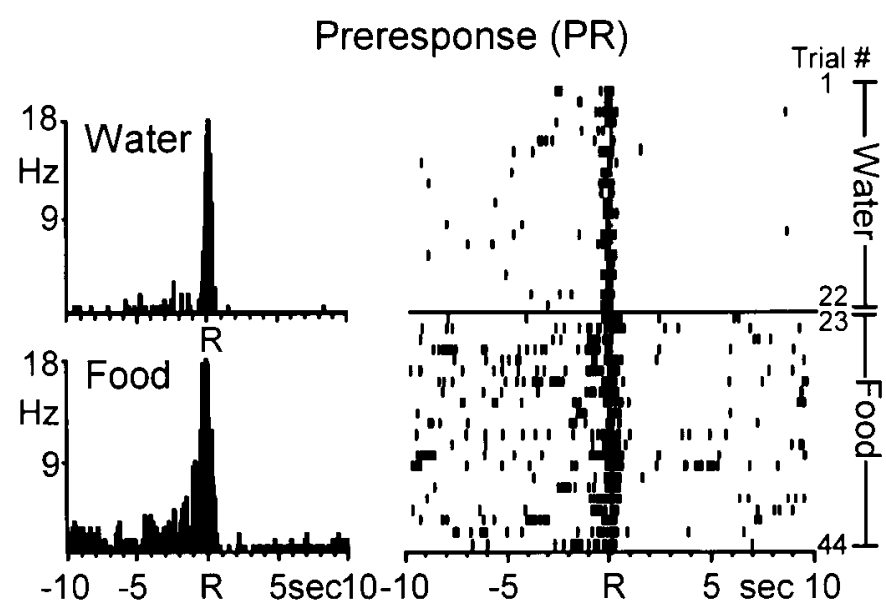

Figure 2. A single Acb cell showing similar anticipatory discharges during the multiple schedule for water and food reinforcement. Left, PEHs show that the Acb cell exhibited type preresponse (PR) activity relative to both the water (top)- and food (bottom)- reinforced response. Each PEH contains 250 bins here and in subsequent figures. Mean INT for water $=25.34 \pm 1.50 \mathrm{sec}$; mean INT for food $=29.75 \pm 2.90 \mathrm{sec}$. $R$ indicates reinforced response here and in subsequent figures. Right, Raster displaying the activity of the same neuron shown in the PEHs across all trials of the multiple schedule. Each row represents a trial (trial number indicated on right) here and in subsequent figures. Trials 1-22, Water reinforcement; trials 23-44, food reinforcement.

ued to display type PR activity but also showed an overall increase in baseline firing rates from $0.13 \mathrm{~Hz}$ (water reinforcement phase) to $1.19 \mathrm{~Hz}$ (food reinforcement phase). Nevertheless, the Acb neuron maintained an anticipatory type PR firing pattern during food-reinforced responding, similar in amplitude and duration to that observed during the water reinforcement phase.

Neurons exhibiting increases in firing rate immediately after water- and food-reinforced responding (type RFe cells) could be divided into two groups. The first group $(n=11$ cells) showed a prolonged increase in firing rate that began $1.19 \pm 0.16 \mathrm{sec}$ after the response for water and food and persisted $8.25 \pm 0.25 \mathrm{sec}$. The second group $(n=7)$ exhibited a short-lasting increase in firing rate that began $0.62 \pm 0.08 \mathrm{sec}$ after the reinforced response and continued $1.06 \pm 0.07 \mathrm{sec}$. An example of an Acb neuron displaying short-duration RFe cell firing across the two natural reinforcer conditions is shown in Figure 3. During the food reinforcement phase (trials 1-29), the cell exhibited a robust increase in firing rate immediately after the response and lasting $\sim 1 \mathrm{sec}$, typical of type RFe activity. During the water reinforcement phase (trials 30-57), the cell had a similar postresponse increase in firing, followed by an inhibition in activity lasting $\sim 7.0$ sec. Nevertheless, the Acb cell maintained the immediate postresponse discharge pattern characteristic of type RFe activity, similar to that observed during the food reinforcement portion of the session.

The third type of neuronal firing pattern was characterized by a marked inhibition in activity relative to background firing rates immediately before and after the response for water or food, characteristic of type RFi activity. The mean onset time of the response inhibition of RFi cells was $0.02 \pm 0.07 \mathrm{sec}$ before the water-reinforced response with a mean duration of $1.45 \pm 0.10$ sec. Likewise, the mean onset time of the response inhibition of RFi cells was $0.07 \pm 0.11 \mathrm{sec}$ before the food-reinforced response with a mean duration of $1.70 \pm 0.11 \mathrm{sec}$. An example of a single 


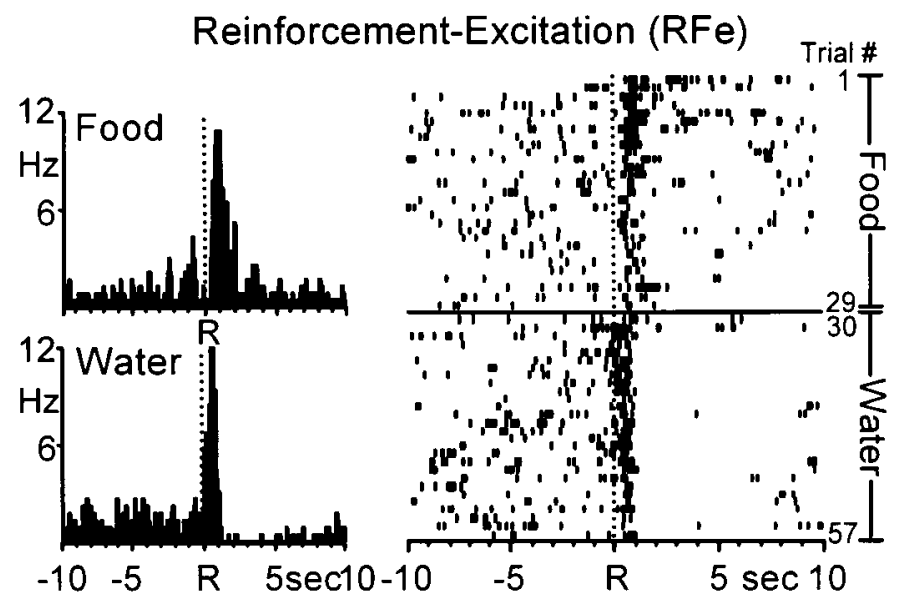

Figure 3. A single Acb cell showing a pronounced increase in firing rate [type reinforcement-excitation $(\mathrm{RFe})$ ] immediately after both the waterand food-reinforced response. Left, PEHs show that the Acb cell exhibited similar type RFe discharge patterns across the food (top) and water (bottom) reinforcer conditions. Mean INT for food $=21.87 \pm 0.19 \mathrm{sec}$; mean INT for water $=21.30 \pm 0.13 \mathrm{sec}$. Right, Raster display shows the activity of the same neuron shown in the PEHs across all trials of the multiple schedule. Trials 1-29, Food; trials 30-57, water.

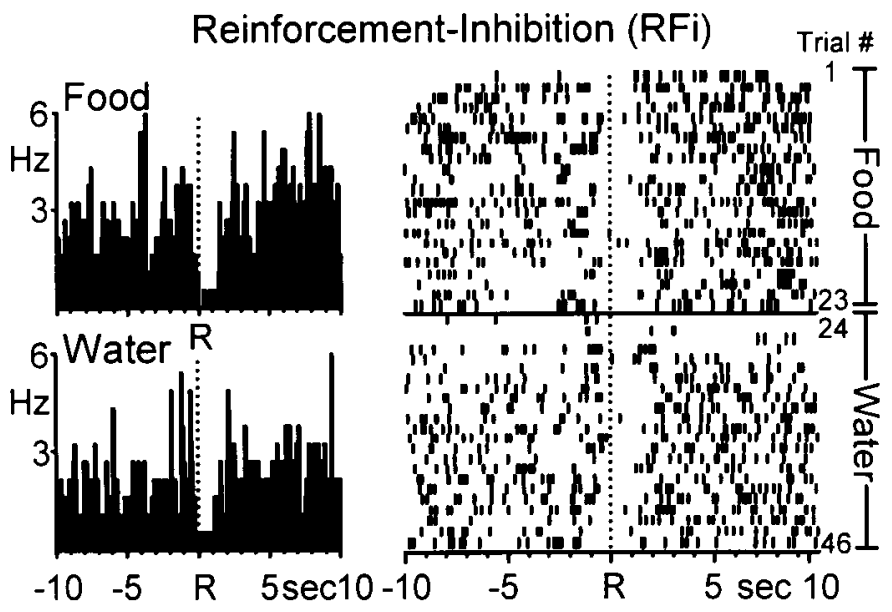

Figure 4. Another Acb cell showing a decrease in firing rate [type reinforcement-inhibition (RFi)] immediately after both water- and foodreinforced responding. Left, PEHs show that the Acb cell exhibited similar type RFi discharge patterns across the food (top) and water (bottom) reinforcer conditions. Mean INT for food $=25.69 \pm 2.39 \mathrm{sec}$; mean INT for water $=21.18 \pm 0.10 \mathrm{sec}$. Right, Raster display shows the activity of the same neuron shown in the PEHs across all trials of the multiple schedule. Trials 1-23, Food; trials 24-46, water.

Acb neuron with similar type RFi activity across the two natural reinforcer conditions is shown in Figure 4.

Mean firing rates for all neurons ( $n=52$ cells) exhibiting similar patterned discharges during the multiple schedule of water and food reinforcement are shown in Table 1. Results indicate that the populations of neurons showed similar peak (types PR, $\mathrm{RFe}$ ) and trough (type RFi) changes in firing rate across the two reinforcer conditions. This finding was statistically verified in that no significant differences in mean peak firing rates were observed for type $\mathrm{PR}(t=0.04 ; p>0.05)$ or type $\mathrm{RFe}(t=0.77 ; p>0.05)$ neurons across the two reinforcer conditions. Likewise, no significant differences were observed in mean trough firing rates for type RFi cells $(t=0.95 ; p>0.05)$ relative to water- versus food-reinforced responding. The composite population PEHs in Figure 5 show a summary of normalized firing of all neurons exhibiting similar types of patterned discharges across the two natural reinforcer conditions. Distinct anticipatory increases in firing can be seen for type PR cells that were similar across the two reinforcer conditions with respect to onset, duration, and relative amplitude in cell firing. The relative increase in type $\mathrm{RFe}$ cells during the water reinforcement phase of the multiple schedule was slightly attenuated but very similar to RFe activity exhibited by the same cells during the food reinforcement phase. Likewise, a third population of neurons classified as type RFi exhibited similar inhibitions in cell firing relative to water- and food-reinforced responding. Collectively, the composite PEHs show the similarity and the complementary nature of Acb cell firing across the two natural reinforcer conditions.

Of the 77 phasically active neurons recorded during the multiple schedule for water and food reinforcement, the remaining 25 phasically active cells (32\%) showed one of the three aforementioned types of patterned discharges relative to reinforced responding for water and food, but not under both conditions. That is, of the 25 neurons, seven cells exhibited either type PR, RFe, or $\mathrm{RFi}$ activity relative to the water-reinforced response, but the same neurons exhibited nonphasic firing relative to the foodreinforced response. In contrast, 12 of the 25 phasically active cells exhibited patterned firing relative to the food-reinforced response and nonphasic activity relative to the reinforced response for water. The remaining six cells exhibited either type $\mathrm{PR}$, RFe, or RFi activity relative to the water- and foodreinforced response, but not the same type of firing pattern across the two natural reinforcer conditions. No type PR+RF neurons were observed during the multiple schedule for water and food reinforcement.

\section{Water and cocaine reinforcement: behavioral performance}

Figure 6 shows the lever press response pattern for a well-trained animal responding on a multiple schedule for water and cocaine reinforcement. The cumulative record from time $0-10$ min shows the water reinforcement portion of the session during which the animal completed 23 responses with a mean INT of $25.40 \pm 1.59$ sec. This was followed by a $20 \mathrm{sec}$ time out period (indicated by double line in the record). The remaining record shows the cocaine self-administration portion of the session. The animal completed an initial burst of four responses (termed load-up behavior), followed by 14 regularly spaced responses with a mean INT of $6.45 \pm 0.51 \mathrm{~min}$. For all animals $(n=8)$, the mean number of responses for water reinforcement was $23.87 \pm 0.91$ with a mean INT of $37.12 \pm 5.73 \mathrm{sec}$. The mean number of responses for cocaine reinforcement across all animals was $24 \pm$ 1.80 with a mean INT of $4.78 \pm 0.20 \mathrm{~min}$. In sessions in which the cocaine self-administration phase preceded water reinforcement, animals typically paused after the time out phase for 12-20 min, and water-reinforced responding was sometimes more erratic compared to sessions in which water preceded cocaine.

\section{The majority of Acb neurons exhibit differential, nonoverlapping firing patterns during water and cocaine reinforcement}

A major finding of the present study was the lack of overlapping neuronal firing patterns relative to operant responding for water and cocaine. Specifically, a total of 127 neurons $(n=8$ rats) were recorded during the multiple schedule for water reinforcement and intravenous self-administration of cocaine. In general, cells 
Table 1. Mean \pm SEM of Acb peak (PR and RFe) and trough (RFi) firing rates across four time epochs relative to the water- or food-reinforced response

\begin{tabular}{|c|c|c|c|c|c|c|}
\hline \multirow[b]{2}{*}{ Epoch (sec) } & \multicolumn{2}{|c|}{ Type PR $(n=12)$} & \multicolumn{2}{|c|}{ Type RFe $(n=18)$} & \multicolumn{2}{|c|}{ Type RFi $(n=22)$} \\
\hline & Water & Food & Water & Food & Water & Food \\
\hline \multicolumn{7}{|l|}{ Baseline } \\
\hline-10 to -7.5 & $4.27 \pm 1.55$ & $5.14 \pm 1.41$ & $2.79 \pm 0.53$ & $2.90 \pm 0.61$ & $5.41 \pm 1.18$ & $5.82 \pm 1.19$ \\
\hline \multicolumn{7}{|l|}{ Response } \\
\hline-2.5 to 0 & $9.28 \pm 2.49$ & $9.33 \pm 2.47$ & $2.81 \pm 0.49$ & $2.74 \pm 0.51$ & $3.73 \pm 0.78$ & $4.85 \pm 1.13$ \\
\hline \multicolumn{7}{|l|}{ Reinforcement } \\
\hline 0 to 2.5 & $4.28 \pm 1.43$ & $4.39 \pm 1.46$ & $4.41 \pm 0.65$ & $4.75 \pm 0.68$ & $1.88 \pm 0.39$ & $2.36 \pm 0.76$ \\
\hline \multicolumn{7}{|l|}{ Recovery } \\
\hline 7.5 to 10 & $3.90 \pm 1.54$ & $4.65 \pm 1.71$ & $3.96 \pm 0.81$ & $4.11 \pm 0.89$ & $5.91 \pm 1.29$ & $6.38 \pm 1.28$ \\
\hline
\end{tabular}

Boldface type denotes significant difference $(p<0.05)$ compared to baseline within the same cell type.
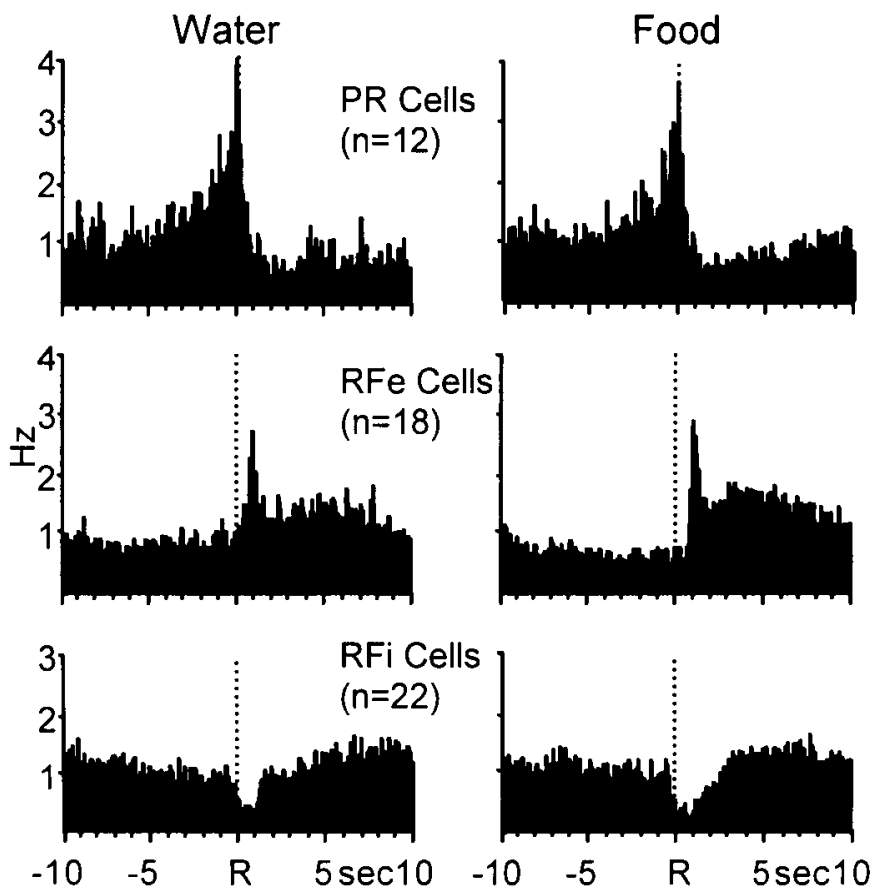

Figure 5. Composite PEHs of normalized firing of all PR, RFe, and RFi cells during water $(l e f t)$ - and food (right)-reinforced responding. Neural activity was normalized relative to the respective overall mean firing rates of each cell here and in Figures 8 and 10. These PEHs therefore reflect the relative increase in firing of each cell type regardless of absolute firing rate. Under both water and food reinforcement conditions, the complementary nature of the relative firing patterns of each cell type is apparent and similar.

fired at lower rates during responding for cocaine (overall mean $=2.56 \pm 0.36 \mathrm{~Hz}$ ) compared to water (overall mean $=$ $3.06 \pm 0.33 \mathrm{~Hz}$ ), consistent with previous findings (Carelli and Deadwyler, 1994). Of 127 cells, 60 (47\%) exhibited patterned discharges relative to the water- or cocaine-reinforced response. However, of the 60 responsive neurons, only five cells (8\%) showed similar patterned discharges relative to reinforced responding for water and cocaine. The remaining 55 neurons (92\%) exhibited one of three types of patterned discharges (type PR, $\mathrm{RFe}$, or RFi cells) relative to the water-reinforced response $(n=$ 29 cells; Table 2), or one of four types of phasic firing patterns (type PR, RFe, RFi, or PR+RF cells) during the cocaine selfadministration component of the multiple schedule ( $n=26$ cells; Table 3), but not both.

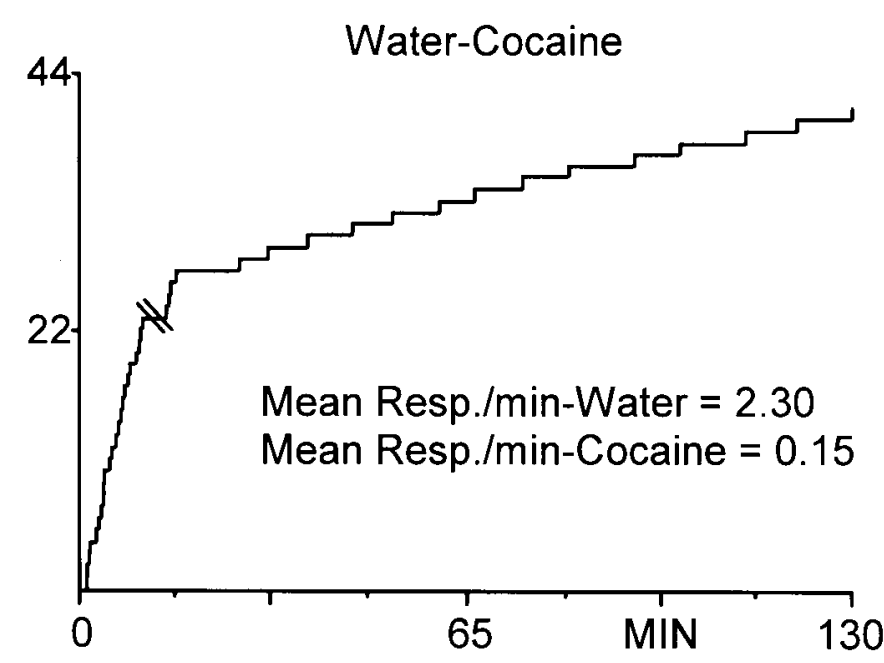

Figure 6. Cumulative record showing the behavioral (lever press) response pattern for a single animal during the multiple schedule for water reinforcement and cocaine self-administration. The animal completed 23 responses for water (mean INT $=25.40 \pm 1.59 \mathrm{sec}$ ), followed by a $20 \mathrm{sec}$ time out period (indicated by double line in record). During the selfadministration phase, the animal completed four responses in quick succession followed by an additional 14 regularly spaced responses (mean INT, $6.45 \pm 0.51 \mathrm{~min}$ ). The $y$-axis is the number of lever presses. Each upward deflection indicates a reinforced response (FR1). Note that the slope difference between this graph and Figure 1 is related to differences in the timebases (minutes vs seconds).

\section{Patterned cell firing specific to water reinforcement}

One population of neurons exhibited patterned discharges relative to the water-reinforced response, whereas the same neurons showed no change in activity from baseline firing rates during the self-administration portion of the multiple schedule. Figure 7 shows an example of a single Acb cell that displayed differential activity relative to water- versus cocaine-reinforced responding. In this case, the same Acb cell was recorded across two consecutive sessions (days) thereby enabling an examination of the responsiveness of this neuron when the reinforcer order was reversed. The top two PEHs (labeled "Session 1") show that the Acb neuron exhibited type PR activity relative to the waterreinforced response and nonphasic cell firing during cocaine self-administration. The corresponding rasters to the right show the activity of the same neuron in the PEHs, across all trials in the session. Note that the Acb cell exhibited patterned type PR activity across all trials of water-reinforced responding (trials 


\begin{tabular}{|c|c|c|c|c|c|c|}
\hline \multirow[b]{2}{*}{ Epoch (sec) } & \multicolumn{2}{|c|}{ Type PR $(n=14)$} & \multicolumn{2}{|c|}{ Type RFe $(n=9)$} & \multicolumn{2}{|c|}{ Type RFi $(n=6)$} \\
\hline & Water & Cocaine & Water & Cocaine & Water & Cocaine \\
\hline \multicolumn{7}{|l|}{ Baseline } \\
\hline-10 to -7.5 & $2.54 \pm 0.68$ & $1.99 \pm 0.69$ & $3.02 \pm 0.39$ & $1.42 \pm 0.35$ & $2.59 \pm 0.83$ & $0.88 \pm 0.67$ \\
\hline \multicolumn{7}{|l|}{ Response } \\
\hline-2.5 to 0 & $6.30 \pm 1.49$ & $2.44 \pm 0.84$ & $2.53 \pm 0.50$ & $1.38 \pm 0.29$ & $1.75 \pm 0.49$ & $1.17 \pm 0.69$ \\
\hline \multicolumn{7}{|l|}{ Reinforcement } \\
\hline 0 to 2.5 & $2.98 \pm 0.77$ & $2.29 \pm 0.85$ & $5.77 \pm 1.43$ & $1.03 \pm 0.51$ & $0.96 \pm 0.32$ & $1.03 \pm 0.51$ \\
\hline \multicolumn{7}{|l|}{ Recovery } \\
\hline 7.5 to 10 & $2.37 \pm 0.69$ & $1.86 \pm 0.74$ & $4.64 \pm 0.80$ & $1.58 \pm 0.33$ & $3.31 \pm 1.33$ & $0.95 \pm 0.62$ \\
\hline
\end{tabular}

Boldface type denotes significant difference $(p<0.05)$ compared to baseline within the same column.

Table 3. Mean \pm SEM of Acb neurons exhibiting phasic cell firing relative to the cocaine- but not water-reinforced response

\begin{tabular}{|c|c|c|c|c|c|c|c|c|}
\hline \multirow[b]{2}{*}{ Epoch (sec) } & \multicolumn{2}{|c|}{ Type PR $(n=9)$} & \multicolumn{2}{|c|}{ Type RFe $(n=5)$} & \multicolumn{2}{|c|}{ Type RFi $(n=6)$} & \multicolumn{2}{|c|}{ Type PR+RF $(n=6)$} \\
\hline & Water & Cocaine & Water & Cocaine & Water & Cocaine & Water & Cocaine \\
\hline \multicolumn{9}{|l|}{ Baseline } \\
\hline-10 to -7.5 & $3.63 \pm 1.54$ & $1.85 \pm 0.51$ & $1.22 \pm 0.45$ & $1.67 \pm 0.51$ & $3.57 \pm 1.43$ & $3.09 \pm 1.03$ & $5.73 \pm 2.70$ & $2.18 \pm 0.92$ \\
\hline \multicolumn{9}{|l|}{ Response } \\
\hline-2.5 to 0 & $3.59 \pm 1.52$ & $5.04 \pm 1.13$ & $1.29 \pm 0.49$ & $1.97 \pm 0.84$ & $2.88 \pm 0.89$ & $3.22 \pm 1.26$ & $6.15 \pm 3.87$ & $5.16 \pm 1.75$ \\
\hline \multicolumn{9}{|l|}{ Reinforcement } \\
\hline 0 to 2.5 & $3.15 \pm 1.15$ & $2.31 \pm 0.71$ & $1.29 \pm 0.67$ & $3.65 \pm 0.80$ & $2.60 \pm 0.83$ & $1.49 \pm 0.61$ & $5.03 \pm 3.35$ & $5.67 \pm 2.18$ \\
\hline \multicolumn{9}{|l|}{ Recovery } \\
\hline 7.5 to 10 & $3.53 \pm 1.62$ & $1.42 \pm 0.38$ & $1.03 \pm 0.43$ & $1.30 \pm 0.46$ & $2.87 \pm 0.92$ & $2.93 \pm 0.95$ & $4.99 \pm 3.09$ & $2.07 \pm 0.94$ \\
\hline
\end{tabular}

Boldface type denotes significant difference $(p<0.05)$ compared to baseline within the same column.

1-23) then shifted its activity from type PR to nonphasic (type NP) activity during the initial trials of cocaine-reinforced responding. The additional PEHs and rasters labeled "Session 2" show the activity of the same cell on the next day, when the animal responded for cocaine first, then water reinforcement during the multiple schedule. Note that the neuron continued to exhibit type NP firing during the cocaine self-administration phase, then shifted to type PR activity for the remainder of the session corresponding to the shift from cocaine to water reinforcement.

Table 2 summarizes the mean firing rates across the four analysis epochs for all neurons $(n=29$ cells $)$ with phasic cell firing relative to the water-reinforced response and nonphasic activity relative to the response for cocaine reinforcement. Note that the populations of neurons exhibited significant changes in cell firing relative to their respective baseline rates only during the water reinforcement phase of the multiple schedule. Nonphasic cell firing was observed for the same cells during the cocaine self-administration portion of the multiple schedule. This finding is illustrated in the composite PEHs in Figure 8, which summarize the normalized activity of all neurons exhibiting phasic cell firing specific to water-reinforced responding during the multiple schedule. Neurons displayed one of the three well-defined types of patterned discharges relative to the water-reinforced response (left). However, the same population of cells exhibited nonphasic activity relative to the cocaine-reinforced response (right).

\section{Patterned cell firing specific to cocaine reinforcement}

A second population of neurons exhibited the opposite pattern of activity during the multiple schedule for water and cocaine reinforcement. Specifically, this population of cells showed phasic firing relative to the cocaine-reinforced response, but nonphasic (type NP) activity relative to the reinforced response for water. An example of one Acb neuron exhibiting cocaine-specific patterned discharges is shown in Figure 9. The PEHs and corresponding raster displays show that the Acb cell exhibited type NP activity relative to the water-reinforced response (top) and type PR cell firing during the cocaine self-administration portion of the session (bottom).

Table 3 summarizes the mean firing rates across the four analysis epochs for all neurons $(n=26$ cells) exhibiting phasic cell firing specific to cocaine self-administration behavior. This population of neurons exhibited not only type PR, RFe, and RFi activity, but also showed a fourth type of neuronal discharge previously termed "PR+RF" (Carelli and Deadwyler, 1994). $\mathrm{PR}+\mathrm{RF}$ neurons have two distinct peaks in cell firing, one immediately preceding the reinforced response and terminating at response completion (like PR cells), and a second peak immediately after the response (like RFe cells) with an inhibitory period between the two peaks (like RFi cells). Of the 60 phasically active cells recorded, six neurons (10\%) exhibited type $\mathrm{PR}+\mathrm{RF}$ activity relative to the cocaine-reinforced response. However, the same neurons showed either type PR $(n=1$ cell) or overall increased firing rates indicative of nonphasic activity $(n=$ 5 cells) relative to the water-reinforced response during the multiple schedule. The composite PEHs in Figure 10 summarize the activity of all neurons exhibiting patterned discharges specific to cocaine-reinforced responding.

\section{Acb neurons exhibit differential firing patterns during food and cocaine reinforcement}

For some animals $(n=3)$, food was substituted for water reinforcement in the multiple schedule. Of 37 neurons, 14 cells $(38 \%)$ were categorized as one of the four types of patterned discharges 


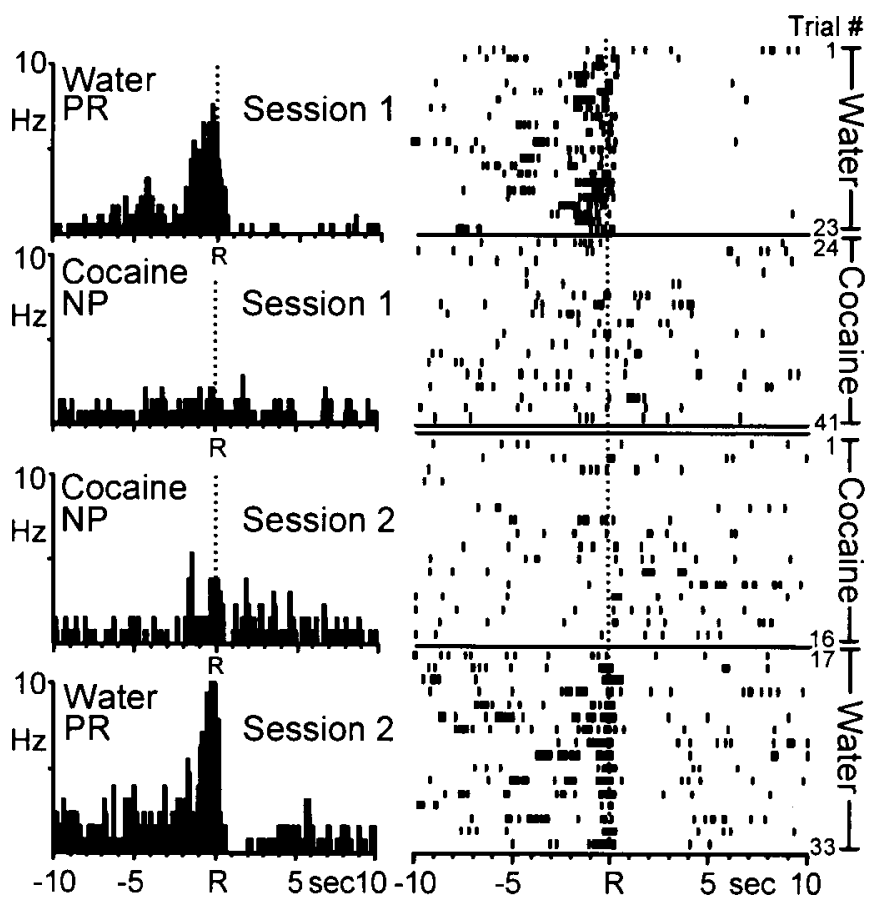

Figure 7. Example of a single Acb neuron recorded during two consecutive sessions (days) in which the order of reinforcer was reversed. Left, PEHs show that the Acb cell exhibited type PR activity relative to the water-reinforced response and nonphasic $(N P)$ activity relative to cocaine-reinforced response across the two sessions. Session 1, Mean INT for water $=25.40 \pm 1.59 \mathrm{sec}$; mean INT for cocaine $=6.86 \pm 0.51 \mathrm{~min}$. Session 2, Mean INT for water $=56.42 \pm 9.76 \mathrm{sec}$; mean INT for cocaine $=7.41 \pm 0.5-1.0 \mathrm{sec} 1 \mathrm{~min}$. Right, Raster displays show the activity of the same neuron shown in the PEHs across all trials. Note that patterned activity specific to water-reinforced responding was observed regardless of reinforcer order in the multiple schedule.

described above. Once again, the majority of phasically active neurons (13 cells, 93\%) showed differential, nonoverlapping firing patterns across the two reinforcer conditions. The PEHs and raster in Figure 11 show an example of one Acb cell that exhibited differential activity during the multiple schedule for food and cocaine reinforcement. The cell displayed a robust increase in firing rate beginning $\sim 0.2 \mathrm{sec}$ after the food-reinforced response and lasting $\sim 10 \mathrm{sec}$, characteristic of type RFe activity (trials 1-29). However, at the start of the self-administration phase of the multiple schedule, the same neuron exhibited an immediate shift in firing to a relatively low baseline rate and type NP activity that was maintained throughout all remaining trials of the session.

\section{Histology}

Detailed inspection of the brains of all 13 animals revealed that the microwire electrode arrays were positioned primarily in the rostral pole, core, and shell subregions of the Acb, as defined by Zahm and Brog (1992). However, for two of thirteen animals tested, microwires in one array per animal were not lowered to the appropriate ventral depth to be situated in the Acb, and were instead placed in the CPv. Therefore, of the 52 cells that exhibited similar types of neuronal firing patterns during the multiple schedule for food and water (experiment 1), four neurons were recorded from microwires clearly positioned in the $\mathrm{CPv}(n=1$ type PR cell, and $n=3$ type RFi neurons; Table 1). Likewise, of the 60 phasically active neurons recorded during the multiple schedule for water and cocaine (experiment 2), six phasically
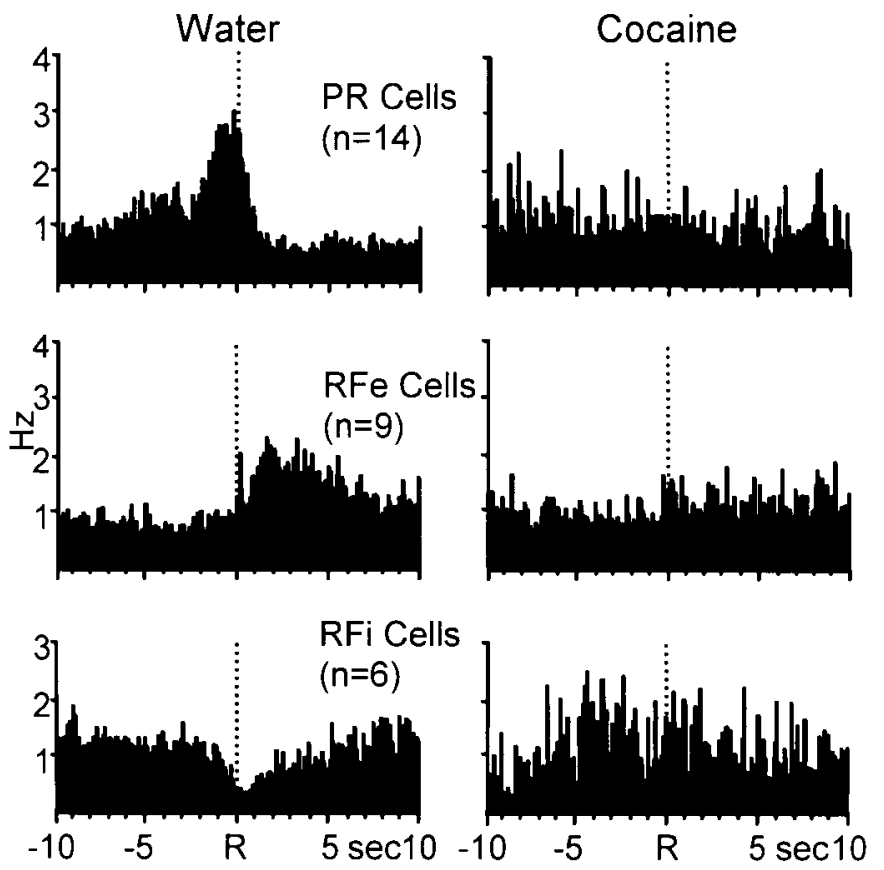

Figure 8. Composite PEHs of normalized firing of all neurons exhibiting patterned discharges relative only to the water-reinforced response. Left, PEHs show that populations of neurons displayed one of the three types of patterned activity relative to the reinforced response for water. Right, The same cells exhibited type NP activity relative the reinforced response for cocaine.

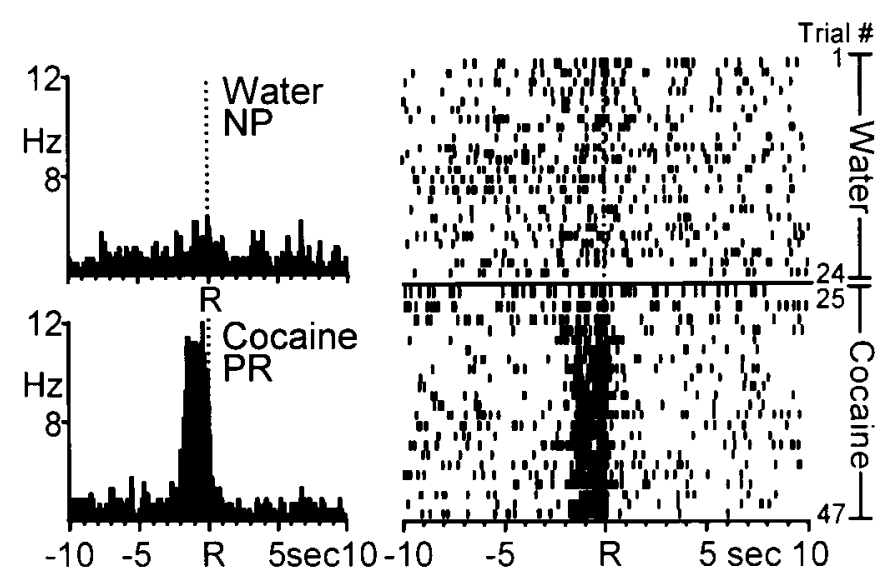

Figure 9. Example of an Acb neuron that exhibited patterned activity relative to cocaine-reinforced responding only. Left, PEHs show that the Acb cell exhibited NP firing relative to the water-reinforced response (top). The same Acb cell exhibited type PR activity relative to the cocaine-reinforced response (bottom). Mean INT for water $=24.39 \pm$ $1.13 \mathrm{sec}$; mean INT for cocaine $=4.43 \pm 0.17 \mathrm{~min}$. Right, Raster display shows the activity of the same neuron shown in the PEHs across all trials of the session. The cell exhibited NP activity during the water reinforcement phase followed by a transition to type PR activity during the initial trials of cocaine self-administration.

active cells were recorded from microwires clearly positioned in the CPv. Of the six neurons, two cells were classified as type PR during the water portion of the multiple schedule (Table 2), whereas the remaining neurons showed phasic firing specific to the cocaine-reinforced response ( $n=1 \mathrm{PR}$ cell; $n=1 \mathrm{RFe}$ cell; $n=2$ RFi cells; Table 3 ). Bilateral electrode placements in the $\mathrm{Acb}$ (core, shell, and rostral pole) and $\mathrm{CPv}$ ranged from +1.00 to 

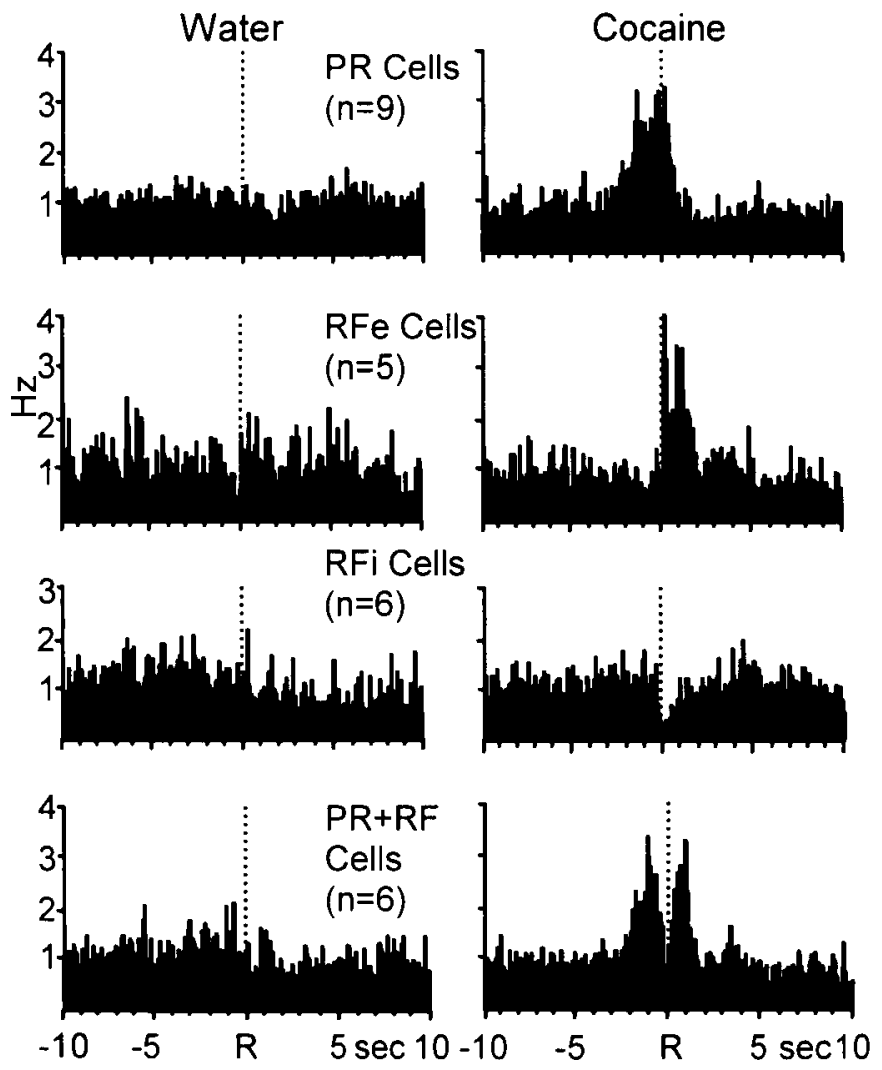

Figure 10. Composite PEHs of normalized firing of all neurons exhibiting patterned discharges relative only to the cocaine-reinforced response during the multiple schedule. Left, PEHs show that populations of neurons exhibited NP activity relative to the reinforced response for water. Right, The same cells exhibited one of the four well-defined types of patterned discharges relative to the cocaine-reinforced response.

$+2.70 \mathrm{~mm}$ anterior to bregma and from 0.40 to $2.4 \mathrm{~mm}$ lateral to the midline. Figure 12 shows the distribution of marked and estimated "unmarked" electrode placements across all animals $(n=13)$ on coronal sections of the stereotaxic atlas of Paxinos and Watson (1997).

\section{DISCUSSION}

The present findings show that in well trained animals cocaine activates a population of neurons in the Acb that are generally not responsive during operant behaviors for water and food reinforcement. This is consistent with a previous study in monkeys showing a dissociation between Acb patterned activity during responding for juice and cocaine (Bowman et al., 1996). However, the present study extends that report by showing that such a separation in Acb cell firing does not typically exist when animals respond on a multiple schedule for water and food reinforcement. These findings provide evidence that separate neural circuits in the Acb function to encode information about drug (cocaine) versus natural (food/water) reward. Furthermore, these results are consistent with studies showing that selective lesions and/or pharmacological manipulation of the mesolimbic system can alter cocaine self-administration but leave operant responding for natural reinforcers relatively unaltered (Caine and Koob, 1994; Glowa and Wojnicki, 1996; Weissenborn et al., 1997; Mello and Negus, 1998; Tran-Nguyen et al., 1999; Wojnicki et al., 1999).
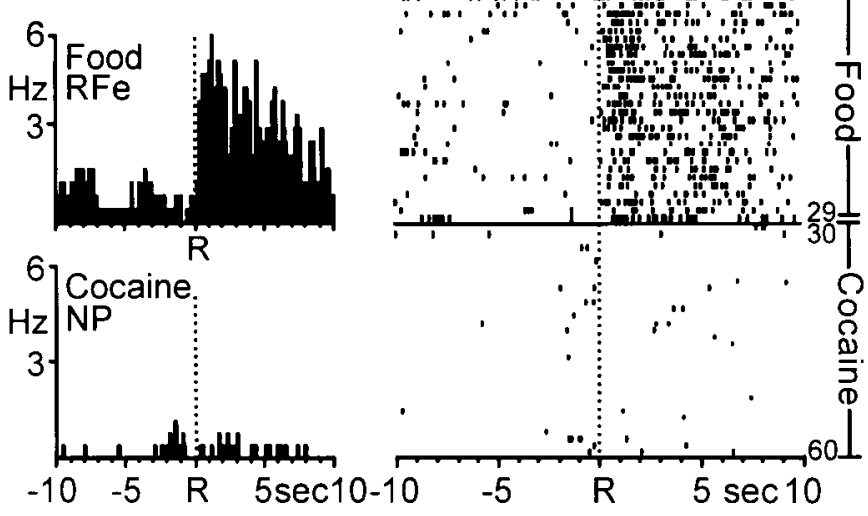

Figure 11. Activity of a single Acb cell during the multiple schedule for food and cocaine reinforcement. Left, PEHs show that the Acb cell exhibited type RFe activity relative to the food-reinforced response (top). The same Acb cell exhibited NP activity relative to the cocainereinforced response (bottom). Mean INT for food $=20.81 \pm 0.04 \mathrm{sec}$; mean INT for cocaine $=4.16 \pm 0.14 \mathrm{~min}$. Right, Raster display shows the activity of the same neuron shown in the PEHs across all trials (number indicated at far right) of the multiple schedule. The transition to NP activity during the self-administration portion of the multiple schedule was immediate, and maintained throughout the remainder of the session.

\section{Acb cell firing during responding for natural (water and food) reward}

A number of studies indicate that the Acb is an important neural substrate mediating feeding and drinking behaviors (Hoebel, 1997; Salamone et al., 1997; Stratford and Kelley, 1997; Rada et al., 1998; Wise, 1998). For example, feeding behavior in rats has been induced via microinf usion of dopamine, non-NMDA glutamate receptor antagonists or GABA agonists into the shell region of the Acb (Kelley and Swanson, 1997; Stratford and Kelley, 1997; Swanson et al., 1997; Stratford et al., 1998). In addition, microdialysis and voltammetry studies revealed significant increases in dopamine levels in the Acb during feeding and drinking in rats (Pfaus et al., 1990; Wenkstern et al., 1993; Di Chiara, 1995; Wilson et al., 1995; Taber and Fibiger, 1997; but see Salamone et al., 1997). A one-to-one correspondence between electrode placement in a particular subregion of the Acb and neuronal firing pattern (cell type) was not determined in the present study. Nevertheless, results reported here clearly show that Acb neurons exhibit patterned activation relative to goal-directed behaviors for water and food reinforcement consistent with a role of this structure in mediating appetitive (nondrug) reinforced behaviors.

The present study also shows that the majority of phasically active Acb neurons exhibited similar types of neuronal firing patterns across the two natural reinforcer conditions. It is important to note however, that in some instances subtle changes in cell firing were observed for individual neurons during the behavioral session. For example, the neuron shown in Figure 2 exhibited an overall increase in background firing rates during the second phase of the multiple schedule that may reflect differences in reinforcer value or rate of reinforcer consumption. Likewise, this type of information may be encoded by other Acb neurons recorded in the present study that did not show overlapping patterned discharges across the two natural reinforcer conditions. Additional electrophysiological studies are needed to examine these and related issues. 


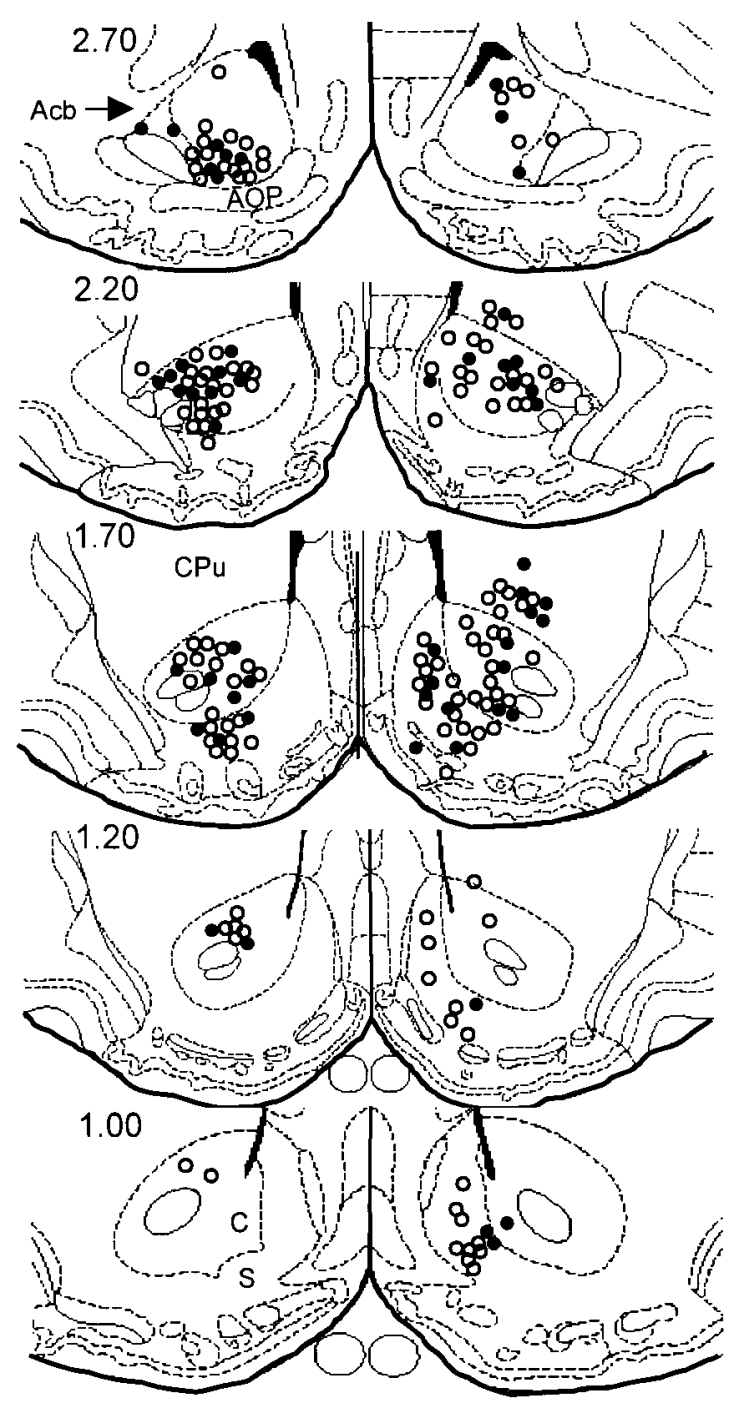

Figure 12. Coronal diagrams showing electrode tip placement of marked and estimated unmarked wires across all 13 animals. Filled circles represent electrode locations that were marked by the presence of a blue dot reaction product (Prussian blue) corresponding to the location of an electrode tip. Open circles indicate estimated position of unmarked electrode tips. Numbers to the left indicate AP coordinates (in millimeters) rostral to bregma. Diagrams were taken from the stereotaxic atlas of Paxinos and Watson (1997). $A c b$, Nucleus accumbens: $S$, nucleus accumbens, shell; $C$, nucleus accumbens, core; $C P u$, caudate putamen.

\section{Acb cell firing during responding for cocaine and natural (water and food) reward}

Electrophysiological studies have shown that Acb cells encode particular aspects of goal-directed responses for water, food, and cocaine (Apicella et al., 1991; Carelli and Deadwyler, 1994, 1997; Chang et al., 1994; Bowman et al., 1996; Peoples and West, 1996; Peoples et al., 1998; Lee et al., 1998). In the present study, the activity of the same Acb neuron was examined during operant responding for cocaine versus a natural (food/water) reinforcer, and an important aspect of Acb cell firing was observed. Specifically, results indicated that one population of Acb neurons appears to selectively encode information about water and food reinforcement while a second subset of Acb cells appears to process information about cocaine reinforcement.

A finding consistent with previous reports was the observance of a fourth neuronal firing pattern observed only during cocaine self-administration and not water reinforcement sessions (termed $\mathrm{PR}+\mathrm{RF}$ or CSp). In the present study, $\mathrm{PR}+\mathrm{RF}$ neurons shifted their activity to either nonphasic or type PR firing during responding for a natural reinforcer in the multiple schedule. These findings support the contention that $\mathrm{PR}+\mathrm{RF}$ activity may represent a form of Acb cell firing related solely to cocaine-reinforced behavior. However, additional studies need to be completed to examine other factors that may influence this type of activity including, for example, changes in the FR requirement or reinforcer value (Schultz et al., 1992; Carelli and Deadwyler, 1994, 1997).

The dissociation in Acb cell firing during goal-directed behaviors for natural versus drug reinforcement provides crucial insight into the functional organization of the Acb. Numerous anatomic studies show that the Acb receives convergent synaptic input from a variety of cortical and subcortical structures, including portions of the prefrontal cortex, subiculum, basolateral amygdala, and the ventral tegmental area (Groenewegen et al., 1991; Zahm and Brog, 1992; Brog et al., 1993; Heimer et al., 1995; Heimer et al., 1997). It has been proposed that the striatum is part of a larger system of functionally segregated circuits that link the basal ganglia and cortex, and that the processing of information within and between these circuits is largely parallel in nature (Alexander et al., 1986; Alexander and Crutcher, 1990; Groenewegen et al., 1996). The present findings support this contention by showing that separate populations of Acb neurons differentially encode information about natural reinforcers (food and water) and cocaine.

Likewise, different types of abused substances (heroin and cocaine) also appear to activate discreet, functionally segregated circuits within the Acb and medial prefrontal cortex (Chang et al., 1998). In that study, neuronal activity was recorded in rats during behavioral sessions involving consecutive self-administration of cocaine and heroin. Results indicated that the majority of Acb neurons exhibited differential firing patterns across the two drug reinforcer conditions that were not attributed solely to differences in locomotor behavior. Collectively, these findings provide evidence that the Acb is part of a complex neural circuit comprising separate functional networks that process specific types of reinforcement-related information.

This is consistent with another theoretical review of the functional organization of the Acb by Pennartz et al. (1994). Those authors proposed that the Acb comprises a collection of neuronal "ensembles" or groups of cells with different functional properties. The activation of specific neuronal ensembles is modifiable depending on reward-related learning processes. In the present study, animals completed the same behavioral response requirement for natural and drug reward, yet subsets of Acb neurons were responsive only under specific reinforcer conditions. These findings illustrate the dynamic nature of Acb cell firing and the ability of single Acb neurons to reorganize activity related to reinforcer-specific circumstances.

\section{Concluding remarks}

The present findings show that the majority of Acb neurons tested exhibited similar neuronal firing patterns during responding for two natural (food and water) reinforcers yet differential activity during operant responding for a natural reinforcer versus cocaine self-administration. These findings provide evidence that separate neural circuits exist in the Acb that encode information related to cocaine versus natural (food/water) reinforcement. It 
remains unclear, however, precisely what functional neural circuit in the Acb is being activated by cocaine. One possibility is that cocaine activates populations of cells that normally process information about the reinforcing properties of sexual behavior (Everitt, 1990; Pfaus et al., 1990; Wenkstern et al., 1993; Childress et al., 1998). Alternatively, cocaine may not be activating a specific type of reinforcer-related circuit, but may instead be "tapping into" a more generalized neural system that is involved in processing, for example, incentive motivational factors associated with positive reinforcement (Stewart et al., 1984).

The majority of neurons recorded in the present study were from electrodes located in the rostral pole, core, and shell of the Acb. In some cases however, the microelectrode array was clearly not lowered to the appropriate ventral depth, and neurons were recorded from the $\mathrm{CPv}$. Although only a small portion of the total sample, $\mathrm{CPv}$ neurons exhibited similar types of patterned discharges as that observed for Acb neurons. These findings may reflect similar firing characteristics of neurons within the $\mathrm{CPv}$ and Acb, consistent with reports showing similarities in limbic structure projections to both regions (Heimer et al., 1995; Wright et al., 1996).

Several important issues remain to be determined with respect to the nature and control of Acb activity reported here. Although it is likely that the dissociation in cell firing reflects the differential encoding by Acb neurons of drug and natural rewards, it is also possible that other factors not specifically tested could also contribute to the present findings (e.g., differences in consummatory behaviors, and/or deprivation state of the animals). It will also be important to examine Acb activity after alterations in the value of the natural reinforcer (e.g., from water to sucrose), changes in the schedule requirement, manipulations in "cost-benefit" requirements, and with respect to the anatomic subdivisions of the Acb (Cousins et al., 1996; Sokolowski and Salamone, 1998; Kelley, 1999; Bassareo and Di Chiara, 1999). Nevertheless, the dissociation in Acb cell firing during responding for cocaine versus natural reinforcers is consistent with the possibility proposed by others that pharmacotherapies for cocaine addiction can be developed that may modify drug-taking behavior while leaving food and water consumption relatively intact (Caine and Koob, 1994; Glowa and Fantegrossi, 1997; Mello and Negus, 1998; Wojnicki et al., 1999).

\section{REFERENCES}

Alexander GE, Crutcher MD (1990) Functional architecture of basal ganglia circuits: neural substrates of parallel processing. Trends Neurosci 13:266-271.

Alexander GE, DeLong MR, Strick PL (1986) Parallel organization of functionally segregated circuits linking basal ganglia and cortex. Annu Rev Neurosci 9:357-381.

Apicella P, Ljungberg T, Scarnati E, Schultz W (1991) Responses to reward in monkey dorsal and ventral striatum. Exp Brain Res $85: 491-500$.

Bardo MT (1998) Neuropharmacological mechanisms of drug reward: beyond dopamine in the nucleus accumbens. Crit Rev Neurobiol 12:37-67.

Bassareo V, Di Chiara G (1999) Differential responsiveness of dopamine transmission to food-stimuli in nucleus accumbens shell/core compartments. Neuroscience 89:637-641.

Bowman EM, Aigner TG, Richmond BJ (1996) Neural signals in the monkey ventral striatum related to motivation for juice and cocaine rewards. J Neurophysiol 75:1061-1073.

Brog JS, Salyapongse A, Deutch AY, Zahm DS (1993) The patterns of afferent innervation of the core and shell in the "accumbens" part of the rat ventral striatum: immunohistochemical detection of retrogradely transported fluoro-gold. J Comp Neurol 338:255-278.

Caine SB, Koob GF (1994) Effects of mesolimbic dopamine depletion on responding maintained by cocaine and food. J Exp Anal Behav 61:213-221.

Carelli RM, Deadwyler SA (1994) A comparison of nucleus accumbens neuronal firing patterns during cocaine self-administration and water reinforcement in rats. J Neurosci 14:7735-7746.

Carelli RM, Deadwyler SA (1996) Dose-dependent transitions in nucleus accumbens cell firing and behavioral responding during cocaine selfadministration sessions in rats. J Pharmacol Exp Ther 277:385-393.

Carelli RM, Deadwyler SA (1997) Cellular mechanisms underlying reinforcement-related processing in the nucleus accumbens: electrophysiological studies in behaving animals. Pharmacol Biochem Behav 57:495-504.

Carelli RM, Ijames S, Konstantopoulos J, Deadwyler SA (1999) Examination of factors mediating the transition to behaviorally correlated nucleus accumbens cell firing during cocaine self-administration in rats. Behav Brain Res 104:127-139.

Chang JY, Sawyer SF, Lee RS, Woodward DJ (1994) Electrophysiological and pharmacological evidence for the role of the nucleus accumbens in cocaine self-administration in freely moving rats. J Neurosci 14:1224-1244.

Chang JY, Janak PH, Woodward DJ (1998) Comparison of mesocorticolimbic neuronal responses during cocaine and heroin selfadministration in freely moving rats. J Neurosci 18:3098-3115.

Childress AR, McElgin W, Mozley D, O'Brien CP (1998) PET imaging of cue-induced and no-drug craving states. Soc Neurosci Abstr 24:1967.

Cousins MS, Atherton A, Turner L, Salamone JD (1996) Nucleus accumbens dopamine depletions alter relative response allocation in a T-maze cost/benefit task. Behav Brain Res 74:189-197.

Di Chiara G (1995) The role of dopamine in drug abuse viewed from the perspective of its role in motivation. Drug Alcohol Depend 38:95-137.

Everitt BJ (1990) Sexual motivation: a neural and behavioural analysis of the mechanisms underlying appetitive and copulatory responses in male rats. Neurosci Biobehav Rev 14:217-232.

Glowa JR, Fantegrossi WE (1997) Effects of dopaminergic drugs on food- and cocaine-maintained responding. IV. Continuous cocaine infusions. Drug Alcohol Depend 45:71-79.

Glowa JR, Wojnicki FHE (1996) Effects of drug on food- and cocainemaintained responding. III. Dopaminergic antagonists. Psychopharmacology 128:351-358.

Green JD (1958) A simple microelectrode for recording from the central nervous system. Nature 182:962.

Groenewegen HJ, Berendse HW, Meredith GE, Haber SN, Voorn P, Walters JG, Lohman AHM (1991) Functional anatomy of the ventral, limbic system-innervated striatum. In: The mesolimbic dopamine system: from motivation to action. (Willner P, Scheel-Kruger J, eds), pp 19-59. New York: Wiley.

Groenewegen HJ, Wright CI, Beijer AV (1996) The nucleus accumbens: gateway for limbic structures to reach the motor system? Prog Brain Res 107:485-511.

Heimer L, Zahm DS, Alheid GF (1995) Basal ganglia. In: The rat nervous system, Ed 2. (Paxinos G, ed), pp 579-628. San Diego: Academic.

Heimer L, Alheid GF, de Olmos JS, Groenewegen HJ, Haber SN, Harlan RE, Zahm DS (1997) The accumbens: beyond the core-shell dichotomy. J Neuropsychiatry Clin Neurosci 9:354-381.

Hoebel BG (1997) Neuroscience and appetitive behavior research: 25 years. Appetite 29:119-133.

Hollerman JR, Tremblay L, Schultz W (1998) Influence of reward expectation on behavior-related neuronal activity in primate striatum. J Neurophysiol 80:947-963.

Kelley AE (1999) Functional specificity of ventral striatal compartments in appetitive behaviors. Ann NY Acad Sci 877:71-90.

Kelley AE, Swanson CJ (1997) Feeding induced by blockade of AMPA and kainate receptors within the ventral striatum: a microinfusion mapping study. Behav Brain Res 89:107-113.

Koob GF (1998) Circuits, drugs, and drug addiction. Adv Pharmacol 42:978-982.

Koob GF, Nestler EJ (1997) The neurobiology of drug addiction. J Neuropsychiatry Clin Neurosci 9:482-497.

Lee RS, Koob GF, Henriksen SJ (1998) Electrophysiological responses of nucleus accumbens neurons to novelty stimuli and exploratory behavior in the awake, unrestrained rat. Brain Res 799:317-322.

Mello NK, Negus SS (1998) Effects of kappa opioid agonists on cocaineand food-maintained responding by rhesus monkeys. J Pharmacol Exp Ther 286:812-824. 
Nicolelis MAL (1999) Methods for neural ensemble recordings. Boca Raton, FL: CRC.

Nicolelis MAL, Ghazanfar AA, Faggin BM, Votaw S, Oliveira LMO (1997) Reconstructing the engram: simultaneous, multisite, many single neuron recordings. Neuron 18:529-537.

Paxinos G, Watson C (1997) The rat brain in stereotaxic coordinates, Compact third edition. San Diego: Academic.

Pennartz CM, Groenewegen HJ, Lopes da Silva FH (1994) The nucleus accumbens as a complex of functionally distinct neuronal ensembles: an integration of behavioral, electrophysiological and anatomical data. Prog Neurobiol 42:719-761.

Peoples LL, West MO (1996) Phasic firing of single neurons in the rat nucleus accumbens correlated with the timing of intravenous cocaine self-administration. J Neurosci 16:3459-3473.

Peoples LL, Gee F, Bibi R, West MO (1998) Phasic firing time locked to cocaine self-infusion and locomotion: dissociable firing patterns of single nucleus accumbens neurons in the rat. J Neurosci 18:7588-7598.

Pfaus JG, Damsma G, Nomikos GG, Wenkstern DG, Blaha CD, Phillips AG, Fibiger HC (1990) Sexual behavior enhances central dopamine transmission in the male rat. Brain Res 530:345-348.

Rada P, Mark GP, Hoebel BG (1998) Galanin in the hypothalamus raises dopamine and lowers acetylcholine release in the nucleus accumbens: a possible mechanism for hypothalamic initiation of feeding behavior. Brain Res 798:1-6.

Richardson NR, Gratton A (1996) Behavior-relevant changes in nucleus accumbens dopamine transmission elicited by food reinforcement: an electrochemical study in rat. J Neurosci 16:8160-8169.

Salamone JD, Cousins MS, Snyder BJ (1997) Behavioral functions of nucleus accumbens dopamine: empirical and conceptual problems with the anhedonia hypothesis. Neurosci Biobehav Rev 21:341-359.

Schultz W (1998) Predictive reward signal of dopamine neurons. J Neurophysiol 80:1-27.

Schultz W, Apicella P, Scarnati E, Ljungberg T (1992) Neuronal activity in monkey ventral striatum related to expectation of reward. J Neurosci 12:4595-4610.

Schultz W, Dayan P, Montague PR (1997) A neural substrate of prediction and reward. Science 275:1593-1599.

Sokolowski JD, Salamone JD (1998) The role of accumbens dopamine in lever pressing and response allocation: effects of 6-OHDA injected into the core and dorsomedial shell. Pharmacol Biochem Behav 59:557-566.

Stewart J, deWit H, Eikelboom R (1984) Role of unconditioned and conditioned drug effects in the self-administration of opiates and stimulants. Psychol Rev 91:251-268.

Stratford TR, Kelley AE (1997) GABA in the nucleus accumbens shell participates in the central regulation of feeding behavior. J Neurosci 17:4434-4440.
Stratford TR, Swanson CJ, Kelley A (1998) Specific changes in food intake elicited by blockade or activation of glutamate receptors in the nucleus accumbens shell. Behav Brain Res 93:43-50.

Swanson CJ, Heath S, Stratford TR, Kelley AE (1997) Differential behavioral responses to dopaminergic stimulation of nucleus accumbens subregions in the rat. Pharmacol Biochem Behav 58:933-945.

Taber MT, Fibiger HC (1997) Feeding-evoked dopamine release in the nucleus accumbens: regulation by glutaminergic mechanisms. Neuroscience 76:1105-1112.

Tran-Nguyen LTL, Baker DA, Grote KA, Solano J, Neisewander JL (1999) Serotonin depletion attenuates cocaine-seeking behavior in rats. Psychopharmacology 146:60-66.

Tremblay L, Hollerman JR, Schultz W (1998) Modifications of reward expectation-related neuronal activity during learning in primate striatum. J Neurophysiol 80:964-977.

Weissenborn R, Robbins TW, Everitt BJ (1997) Effects of medial prefrontal or anterior cingulate cortex lesions on responding for cocaine under fixed-ratio and second-order schedules of reinforcement in rats. Psychopharmacology 134:242-257.

Wenkstern D, Pfaus JG, Fibiger HC (1993) Dopamine transmission increases in the nucleus accumbens of male rats during their first exposure to sexually receptive female rats. Brain Res 618:41-46.

Wilson C, Nomikos GG, Collu M, Fibiger HC (1995) Dopaminergic correlates of motivated behavior: Importance of drive. J Neurosci 15:5169-5178.

Wise RA (1982) Common neural basis for brain stimulation reward, drug reward, and food reward. In: The neural basis of feeding and reward (Hoebel BG and Novin D, eds), pp 445-454. Brunswick, ME: Haer Institute.

Wise RA (1983) Brain neuronal systems mediating reward processes. In: The neurobiology of opiate reward processes. (Smith JE, Lane JD, eds), pp 405-437. New York: Elsevier.

Wise RA (1997) Drug self-administration viewed as ingestive behavior. Appetite 28:1-5.

Wise RA (1998) Drug-activation of brain reward pathways. Drug Alcohol Depend 51:13-22.

Wojnicki FHE, Rothman RB, Rice KC, Glowa JR (1999) Effects of phentermine on responding maintained under multiple fixed-ratio schedules of food and cocaine presentation in the rhesus monkey. J Pharmacol Exp Ther 288:550-560.

Wright CI, Beijer VJ, Groenewegen HJ (1996) Basal amygdaloid complex afferents to the rat nucleus accumbens are compartmentally organized. J Neurosci 16:1877-1893.

Zahm DS, Brog JS (1992) Commentary: on the significance of subterritories in the "accumbens" part of the rat ventral striatum. Neuroscience 50:751-767. 